\title{
Love in the Time of Corona
}

\section{Seyed Mohammadreza Hashemian ${ }^{1}$, Amir Vahedian-Azimi ${ }^{2}$, Mohamad Amin Pourhoseingholi ${ }^{3}$}

\author{
${ }^{1}$ Chronic Respiratory Diseases Research Center, National Research Institute of Tuberculosis and Lung Diseases, Masih \\ Daneshvari Hospital, Shahid Beheshti University of Medical Sciences, Tehran, Iran \\ ${ }^{2}$ Trauma Research Center, Nursing Faculty, Baqiyatallah University of Medical Sciences, Tehran, Iran \\ ${ }^{3}$ Gastroenterology and Liver Diseases Research Center, Research Institute for Gastroenterology and Liver Diseases, \\ Shahid Beheshti University of Medical Sciences, Tehran, Iran
}

\begin{abstract}
*Corresponding Author: Mohamad Amin Pourhoseingholi, Ph.D., Associate Professor of Biostatistics, Gastroenterology and Liver Diseases Research Center, Research Institute for Gastroenterology and Liver Diseases, Shahid Beheshti University of Medical Sciences, Taleghani Hospital, Velenjak, Tehran, Iran. Tel: +98-9128105208, Email: aminphg@ gmail.com
\end{abstract}

Received February 24, 2020; Accepted March 13, 2020; Online Published March 18, 2020

\section{Dear Editor,}

This is not a doctor and this is not an angle, but both have bloomed in the eye of a person (Figure 1). Both become one. As new hope arrives, the dark clouds go away. This painting says more regarding the burden of disease, burden of fear, and burden of people in our country, Iran.

Imagine a respiratory referral hospital designated as an isolation center, with a crowd of people in the emergency section. Among those standing in line, suddenly one arrives with his companions: a 56-year-old, famous ENT specialist from another hospital is referring directly to our critical care unit; he has tested positive for Coronavirus disease 2019 (COVID-19). His has moderate ARDS, and his O2 sat level is $85 \%$; CXR shows bilateral infiltration. Intermittent non-invasive ventilation is started with nasal high-flow therapy and a reservoir mask. His wife also referred, but her condition was better, and she was sent to the general ward for 2 days. Unfortunately, news was sparse, and many of the ENT specialist's patients and friends thought he had died because of the coronavirus and sent memorials and obituary notices for him.

These are not the only persons routinely referring to a hospital with COVID-19; an outbreak of this novel coronavirus first began in Wuhan, China, ${ }^{1}$ then spread rapidly with cases now confirmed in multiple countries, including ours. Patients in all ranges of age are afflicted; the older ones are at a higher risk of death, but younger ones are not risk-free.

A 25-year-old physician from another hospital also referred here with a diagnosis of H1NI and moderate ARDS; however a second $\mathrm{H} 1 \mathrm{~N} 1$ test was negative. His $\mathrm{O} 2$ saturation level was $80 \%$; CXR showed bilateral infiltration. After 5 days in the ICU, the coronavirus detection kit arrived in Iran; his test result was positive. Although his condition is not generally bad, you can see the fear in his dark eyes, the fear not only visible on his face, but tangible all around. Panic is be seen in the streets, the closed markets and bazaars, in the limited public cultural and artistic programs. Fear creates fear. Panic surrounds us in the metropolis of Tehran, and it resides in every other city in the country, from home to home and from household to household. Self-isolation in their homes for a nation known for closed family relationships has produced upset, emotional tension, and stress, and high levels of stress can disrupt the immune system! The Iranian new year (Nowruz) celebration was coming, but nobody was joyful during this traditional celebration!

For people who have gotten used to living with sanctions, a lack of facilities and resources, political tensions, and the shadow of war, COVID-19 may be the last straw. Each day we are faced with a large group of people who are afraid of this albeit scary disease or being hypochondriacal over a small sneeze! Working in the coronavirus ward is becoming harder and harder for the clinic's staff. The number of infected doctors and nurses is increasing. There are not enough masks or gloves. Access to medicines and medical facilities is limited because of US sanctions. Hope could vanish behind the tears and fears. The country is now ranked among the top ten for highest infected cases and mortality (https://www.worldometers.info/ coronavirus/), according to officially reported statistics, ${ }^{2}$ and it is predicted to experience an even greater burden of mortality and morbidity in the near future. ${ }^{3}$

We tried to send some hopeful news, first, about our famous friend the ENT specialist, simply by making a short clip of him and reporting his improvement. The film spread through the social media, maybe faster than the COVID-19 epidemic spread through the world! There

Copyright (C) 2020 The Author(s). This is an open-access article distributed under the terms of the Creative Commons Attribution License (http:// creativecommons.org/licenses/by/4.0), which permits unrestricted use, distribution, and reproduction in any medium, provided the original work is properly cited. 


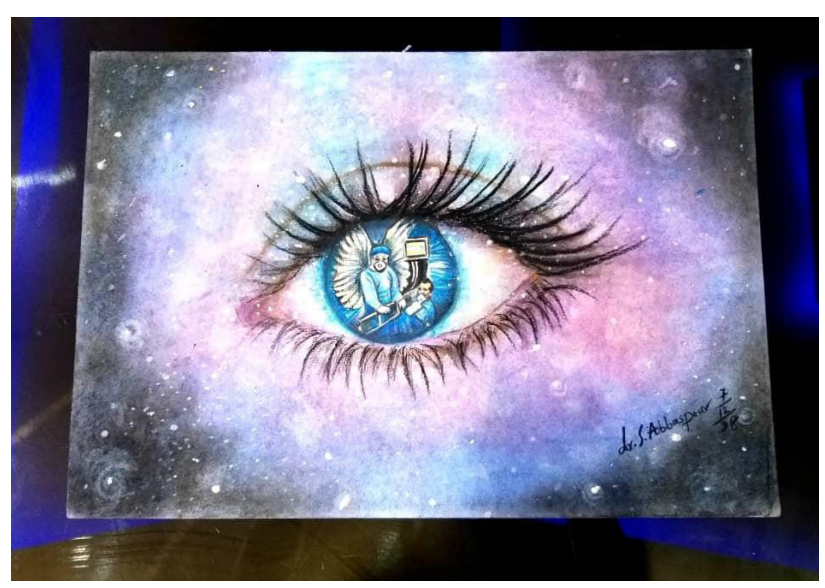

Figure 1. A Painting by Our Colleague, Dr. Sara Abbaspour, Based on the Short Clip of an ENT Specialist as a Patient.

was much positive feedback, and others tried to share their experiences with COVID-19, as a patient, a medical doctor, or a specialist, using social media and their cellphones, and a new epidemic was born: the epidemic of podcast, short films, art, and clips. Social media has become the new weapon against COVID-19. Through viewing patients' video clips in cyberspace, patients' fears of the disease have diminished and a feeling of solidarity and love has been fostered. Humanity unites people like links in a chain.

Much effort was put into preventing the young infected physician from needing intubation using noninvasive mechanical ventilation, high-flow nasal cannula, and the corona protocol. Fortunately, he was discharged from the intensive care unit after surviving a critical condition; he went into the non-critical care unit and was ultimately discharged from the hospital. Before he left, he filmed with his cellphone a short clip of himself and his doctor and expressed his gratitude. In it, one can see hope, happiness, and love. Life was shining in his dark eyes. This is not a reflection of a doctor, or an angel, or even the affection between a doctor and a patient; this is hope and love which is born again in the eyes of a nation, love in the time of corona.

\section{Authors' Contributions}

All authors contributed equally to this study.

\section{Conflict of Interest Disclosures}

The authors declare that they have no conflicts of interest.

\section{Ethical Approval}

Not applicable.

\section{Acknowledgments}

The authors express their appreciation to Doctor Sara Abbaspour for her beautiful and valuable painting.

\section{References}

1. Zhu N, Zhang D, Wang W, et al. A novel coronavirus from patients with pneumonia in China, 2019. N Engl J Med. 2020;382(8):727-733. doi:10.1056/NEJMoa2001017.

2. Coronavirus: the disease Covid-19 explained. https://multimedia.scmp.com/infographics/news/china/article/3047038/ wuhan-virus/index.html? src=article-launcher.

3. Shojaee S, Pourhoseingholi MA, Ashtari S, Vahedian-Azimi A, Asadzadeh-Aghdaei H, Zali MR. Predicting the mortality due to Covid-19 by the next month for Italy, Iran and South Korea; a simulation study. Gastroenterol Hepatol Bed Bench. 2020;13(2):177-179 